\title{
Optimal Design of Liquid Dampers for Structural Vibration Control Based on GA and $H_{\infty}$ Norm
}

\author{
Linsheng Huo, Wenhe Shen, Hongnan Li, and Yaowen Zhang \\ State Key Laboratory of Coastal and Offshore Engineering, Dalian University of Technology, Dalian 116024, China \\ Correspondence should be addressed to Linsheng Huo; lshuo@dlut.edu.cn
}

Received 4 July 2013; Accepted 7 October 2013

Academic Editor: Gang Li

Copyright (c) 2013 Linsheng Huo et al. This is an open access article distributed under the Creative Commons Attribution License, which permits unrestricted use, distribution, and reproduction in any medium, provided the original work is properly cited.

\begin{abstract}
This paper focused on the optimal design of liquid dampers for the seismic response control of structures. The $H_{\infty}$ norm of the transfer function from the ground motion to the structural response is selected as the optimal objective. The optimization procedure is carried out by using Genetic Algorithms (GAs) in order to reach an optimal solution. The proposed method has the advantages that it is unnecessary to solve the equation of motion for the control system and that the obtained optimal parameters of dampers are not dependent on the ground motion records. The influences of weighted functions on the optimization results are analyzed. The generality and effeteness of the proposed method are verified by the time history analysis of a 3-story structure subjected to earthquake records in different sites. The results show that the structural responses can be effectively reduced subjected to earthquake excitation at different sites.
\end{abstract}

\section{Introduction}

The installation of vibration absorbers on tall buildings or other flexible structures can be a successful method for reducing the effects of dynamic excitations, such as strong wind or earthquakes, which may exceed either serviceability or safety criteria. Tuned liquid column damper (TLCD) is an effective passive control device by the motion of liquid in a column container. A TLCD is a U-shaped tube of uniform rectangular or circle cross section, containing liquid. Vibration energy is transferred from the structure to the TLCD liquid through the motion of the rigid container exciting the TLCD liquid. And the vibration of a structure is suppressed by a TLCD through the gravitational restoring force acting on the displaced TLCD liquid and the energy is dissipated by the viscous interaction between the liquid and the rigid container, as well as liquid head loss due to orifices installed inside the TLCD container. The potential advantages of liquid vibration absorbers include low manufacturing and installation costs, the ability of the absorbers to be incorporated during the design stage of a structure or to be retrofitted to serve a remedial role, relatively low maintenance requirements, and the availability of the liquid to be used for emergency purposes or for the everyday function of the structure if fresh water is used $[1,2]$.

Analytical and experimental research works on this type of vibration reduction approach have been conducted, in which viscous interaction between a liquid and solid boundary has been investigated and used to control vibration [3, 4]. Their experiments, defining the relationship between the coefficient of liquid head loss (as well as its dependence on the orifice opening ratio) and the liquid damping, confirm the validity of their proposed equation of motion in describing liquid column relative motion under moderate excitation. A variation of TLCD, called a liquid column vibration absorber (LCVA), has also been investigated, which has different cross-sectional areas in its vertical and horizontal sections depending on performance requirements [5-8]. Yan and $\mathrm{Li}$ presented the adjustable frequency tuned liquid column damper by adding springs to the TLCD system, which modified the frequency of TLCD and expended its application ranges [9]. Gao et al. analyzed the characteristics of multiple liquid column dampers (MTLCD) [10]. It was found that the frequency of range and the coefficient of liquid head loss have significant effects on the performance of a MTLCD; increasing the number of TLCD can enhance the efficiency of 


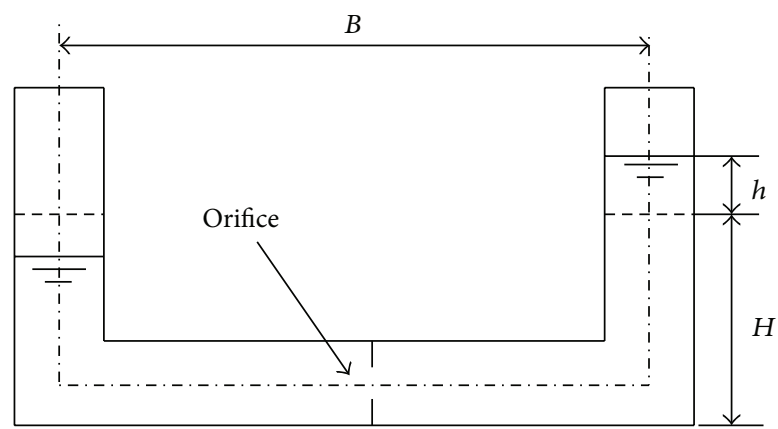

FIgURE 1: Configuration of TLCD.

MTLCD, but no further significant enhancement is observed when the number of TLCD is over five. It was also confirmed that the sensitivity of an optimized MTLCD to its central frequency ratio is not much less than that of an optimized single TLCD to its frequency ratio, and an optimized MTLCD is even more sensitive to the coefficient of head loss.

How to decide the parameters and location of dampers in structures to achieve the optimal response reduction is still an open problem currently. One of the commonly used methods for the optimization of the damper parameters is to set the objective function to be the stochastical response of structures based on the seismic frequency spectrum input and the optimal parameters can be achieved by Genetic Algorithms (GAs). Another commonly used method of optimization is to set the objective function to be the structural responses or their combination in time domain based on the actual earthquake records. The shortcoming for the above two methods is that the equation of motion of the structural system has to be solved in every optimization step, which is time consuming. Besides, the optimal parameters acquired by the above methods are related to specific earthquakes and may not be optimal in some earthquakes. Hence, it is necessary to find a more general and effective method to optimize the parameters of liquid dampers to reduce structural vibration. The active control theory has been used to optimize the parameters of passive control systems and a lot of results have been achieved [11-22]. Based on $H_{\infty}$ norm and Genetic Algorithms (GAs), this paper proposed the optimization method for liquid dampers, which has the advantages that it is unnecessary to solve the equation of motion for the system and that the optimized parameters are not related to specific earthquake records.

\section{Problem Descriptions}

2.1. Equation of Motion for TLCD. The configuration of the tuned liquid column damper (TLCD) is shown in Figure 1. According to Lagrange theory, the equation of motion for TLCD on the structure subjected earthquake excitation is derived as

$$
\rho A(2 H+B) \ddot{h}+\frac{1}{2} \rho A \xi|\dot{h}| \dot{h}+2 \rho A g h=-\rho A B\left(\ddot{x}_{n}+\ddot{x}_{g}\right),
$$

where $\rho$ is the density of the liquid; $h$ is the relative movement of the liquid in TLCD; $H$ is the static height of the liquid in the container; $A$ is the cross-sectional area of TLCD; $g$ is the gravitational acceleration; $B$ is the length of the horizontal part of TLCD; $\xi$ is the coefficient of head loss, which can be controlled by varying the orifice area; $\ddot{x}_{n}$ is the acceleration of the $n$th floor where TLCD is installed; $\ddot{x}_{g}$ is the acceleration of ground motion.

Due to the nonlinear damping of the aforementioned equation, by the equivalently linearization of it (1) can be converted to

$$
m_{T} \ddot{h}+c_{T} \dot{h}+k_{T} h=-\alpha_{x} m_{T}\left(\ddot{x}_{n}+\ddot{x}_{g}\right),
$$

where $m_{T}=\rho A L_{e}$ is the mass of the liquid in the TLCD, $L_{e}=$ $2 H+B$ is the length of the liquid in the TLCD, $c_{T}=(\rho A \xi|\dot{h}|) / 2$ is the equivalent damping of the TLCD, and $k_{T}=2 \rho \mathrm{Ag}$ is the "stiffness" of the liquid in vibration. Hence, the circular frequency of the motion can be written as $\omega_{T}=\sqrt{k_{T} / m_{T}}=$ $\sqrt{2 g / L_{e}} \cdot \alpha_{x}$ is the shape function of the liquid damper, written as $\alpha_{x}=B / L_{e}$.

2.2. Mathematical Model of the Control System. For an $n$-story shear frame structure, the dynamics of the structural building without TLCD can be described as

$$
M \ddot{x}+C \dot{x}+K x=-M I \ddot{x}_{g},
$$

where $M, C$, and $K$ are the mass, damping, and stiffness matrices of the structural building with the dimension of $n \times n$, respectively; $I$ is an identity vector with the dimension of $n \times 1$; the relative displacement vector $x$ is defined as

$$
x=\left[\begin{array}{llll}
x_{1} & x_{2} & \cdots & x_{n}
\end{array}\right]^{T},
$$

where $x_{i}$ is the relative displacement of the $i$ th floor. So the equation of motion for the structural building instrumented with TLCD on the top floor as shown in Figure 2 can be formulated as

$$
M_{s} \ddot{q}+C_{s} \dot{q}+K_{s} q=-M_{s} I \ddot{x}_{g},
$$

where

$$
\begin{gathered}
M_{s}=\left[\begin{array}{cccc}
m_{1} & 0 & 0 & 0 \\
0 & \ddots & 0 & 0 \\
0 & 0 & m_{n}+m_{T} & \alpha m_{T} \\
0 & 0 & \alpha m_{T} & m_{T}
\end{array}\right], \\
K_{s}=\left[\begin{array}{cccc}
k_{1} & 0 & 0 & 0 \\
0 & \ddots & 0 & 0 \\
0 & 0 & k_{n} & 0 \\
0 & 0 & 0 & k_{T}
\end{array}\right], \quad C_{s}=\left[\begin{array}{cccc}
c_{1} & 0 & 0 & 0 \\
0 & \ddots & 0 & 0 \\
0 & 0 & c_{n} & 0 \\
0 & 0 & 0 & c_{T}
\end{array}\right], \\
q=\left(\begin{array}{llll}
q_{1} & \cdots & q_{n} & q_{n+1}
\end{array}\right)^{T}=\left(\begin{array}{llll}
x_{1} & \cdots & x_{n} & h
\end{array}\right)^{T} .
\end{gathered}
$$

The elements $m_{i}, c_{i}$, and $k_{i}$ in matrices $M_{s}, C_{s}$, and $K_{s}$ are the mass, damping, and stiffness of the $i$ th floor. Equation (5) can be expressed by the state space form as

$$
\begin{aligned}
& \dot{z}(t)=A z(t)+B w(t), \\
& y(t)=C z(t)+D w(t),
\end{aligned}
$$




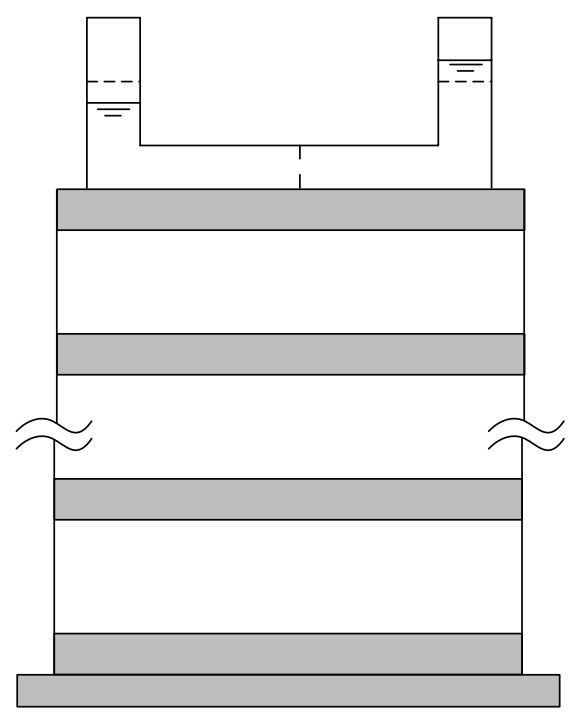

FIgURE 2: The structure with TLCD.

where $z(t)$ and $y(t)$ are, respectively, the state vector and output vector of the system and

$$
\begin{gathered}
z(t)=\left[\begin{array}{c}
q(t) \\
\dot{q}(t)
\end{array}\right], \quad A=\left[\begin{array}{cc}
0 & I \\
-M_{s}^{-1} K_{s} & -M_{s}^{-1} C_{s}
\end{array}\right], \\
B=\left[\begin{array}{c}
0 \\
-I
\end{array}\right], \quad w(t)=\ddot{u}_{g}(t) .
\end{gathered}
$$

The matrices $C$ and $D$ would be determined according to the optimization object.

2.3. $H_{\infty}$ Norm. The transfer function of (7) can be expressed by

$$
T(s)=C(s I-A)^{-1} B+D .
$$

The $H_{\infty}$ norm is defined as

$$
\|T(s)\|_{\infty}=\sup _{w} \sigma_{\max }[T(j w)] .
$$

In another word, the $H_{\infty}$ norm is the maximum singular value of frequency response of the system. In the frequency domain, the $H_{\infty}$ norm can be derived by

$$
\|T(s)\|_{\infty}=\sup _{\|w(t)\|_{2} \neq 0} \frac{\|y(t)\|_{2}}{\|w(t)\|_{2}}=\sup _{\|w(t)\|_{2}=1}\left[\|y(t)\|_{2}\right],
$$

where $\|y(t)\|_{2}$ is the $L_{2}$ norm of the output $y(t)$ and can be determined by the following equation:

$$
\|y(t)\|_{2}=\left(\int_{0}^{\infty} y^{T}(t) y(t) d t\right)^{1 / 2} .
$$

It can be found that $\|y(t)\|_{2}$ is the energy measurement of the output $y(t)$. Similarly, the $L_{2}$ norm of $w(t)$ is the energy measurement of the seismic input, which can be determined by

$$
\|w(t)\|_{2}=\left(\int_{0}^{\infty} w^{T}(t) w(t) d t\right)^{1 / 2}
$$

If the $H_{\infty}$ norm of the transfer function $T(s)$ achieves its minimum, the energy measurement of the output will meet its minimum and the control performance of the system will be in its best state based on $H_{\infty}$ norm.

\section{Selection of the Weighted Function}

Theoretically, the optimum control based on $H_{\infty}$ norm is to meet the minimum of $H_{\infty}$ norm in the frequency domain. However, it is impractical to control the dynamic response of the system in the whole frequency domain due to the property limitation of dampers. Hence, the weighted functions are usually used to regulate the system's performance in the active controller design or parameters optimization of passive dampers. The advantages of using weighted functions are obvious in controller design. First, some components of a vector signal are usually more important than others. Second, each component of the signal may not be measured in the same units. Also, we might be primarily interested in the dynamic response of a certain frequency range [23]. Therefore, some frequency-dependent weights must be chosen to obtain a high performance controller. Two weighted functions, $W_{g}(s)$ and $W_{1}(s)$, will be used to facilitate the parameter optimization of liquid dampers, in which $W_{g}(s)$ and $W_{1}(s)$ are used to weigh the seismic excitation and structural dynamics, respectively. However, there is no definite conclusion how the weighted functions will influence the optimization results and how to select appropriate weighted functions to get the optimal results with less computational efforts. This paper will analyze the influences of weighted functions on the optimal results of liquid dampers.

The weighted function $W_{g}$ is used to reflect the frequency content of an earthquake. The most commonly used stochastic model of earthquakes is the Kanai-Tajimi spectrum, as shown in the following equation:

$$
S(\omega)=S_{0}\left[\frac{\omega_{g}^{4}+4 \omega_{g}^{2} \zeta_{g}^{2} \omega^{2}}{\left(\omega^{2}-\omega_{g}^{2}\right)^{2}+4 \omega_{g}^{2} \zeta_{g}^{2} \omega^{2}}\right] .
$$

The weighted function $W_{g}$ is chosen as the square root of the Kanai-Tajimi spectrum:

$$
W_{g}(s)=\frac{\sqrt{S_{0}}\left(\omega_{g}^{2}+2 \zeta_{g} \omega_{g} s\right)}{s^{2}+2 \zeta_{g} \omega_{g} s+\omega_{g}^{2}} .
$$

The values of $\omega_{g}$ and $\zeta_{g}$ can be determined according to the site types.

For the regulated response, we are only interested in the low-frequency response. Therefore, the weighted function $W_{1}$ can be selected as a low-pass filter. The influences of weighted functions on the optimization results will be discussed in the following section.

\section{Genetic Algorithm}

Genetic Algorithm (GA) is a search heuristic that mimics the process of natural evolution to generate useful solutions to optimization and search problems. In a genetic algorithm, 
a population of candidate solutions to an optimization problem is evolved toward better solutions. Each candidate solution has a set of properties which can be mutated and altered. The evolution usually starts from a population of randomly generated individuals and is an iterative process, with the population in each iteration called a generation. In each generation, the fitness of every individual in the population is evaluated; the fitness is usually the value of the objective function in the optimization problem being solved. The more fit individuals are stochastically selected from the current population, and each individual's property is modified to form a new generation. The new generation of candidate solutions is then used in the next iteration of the algorithm. Commonly, the algorithm terminates when either a maximum number of generations have been produced or a satisfactory fitness level has been reached for the population. A typical genetic algorithm requires a genetic representation of the solution domain and a fitness function to evaluate the solution domain. Once the genetic representation and the fitness function are defined, a GA proceeds to initialize a population of solutions and then to improve it through repetitive application of the mutation, crossover, inversion and selection operators. The steps of problem solution by genetic algorithm can be summarized as follows.

(1) Determine variables and constraint conditions; in other words, determine the individuals' form and the solution space.

(2) Define the fitness function. The fitness function is defined as the $H_{\infty}$ norm of the controlled system.

(3) Find the chromosome coding and decoding method for the feasible solution.

(4) Define the rules of transforming the value of objective function to individual fitness.

(5) Define the genetic operators, which are the methods of selection, crossover, and mutation to generate the next generation.

(6) Choose the parameters of the genetic algorithm, including the population size, iteration number, termination condition, selection probability, crossover probability, and mutation probability.

(7) Run the genetic algorithm and acquire the individuals with maximum fitness values.

\section{Numerical Analysis}

5.1. Structural Parameters. A 3-story frame structure is used as a numerical example to verify the significance of weighted functions. The values of mass, stiffness and damping matrices are, respectively, as follows:

$$
\begin{gathered}
M=\left[\begin{array}{lll}
5 & & \\
& 5 & \\
& 5
\end{array}\right] \times 10^{5} \mathrm{Kg} \\
C=\left[\begin{array}{ccc}
1.3506 & -0.5286 & 0 \\
-0.5286 & 1.3506 & -0.5286 \\
0 & -0.5286 & 0.8220
\end{array}\right] \times 10^{6} \mathrm{~N} \cdot \mathrm{s} / \mathrm{m}, \\
K=\left[\begin{array}{ccc}
4 & -2 & 0 \\
-2 & 4 & -2 \\
0 & -2 & 2
\end{array}\right] \times 10^{8} \mathrm{~N} / \mathrm{m} .
\end{gathered}
$$

The natural frequencies of the structure without control are $1.58 \mathrm{~Hz}, 4.44 \mathrm{~Hz}$, and $6.42 \mathrm{~Hz}$, respectively. A TLCD is installed on the top floor to control the structural vibration.

With the consideration of structural safety, optimization objective is set to make the $H_{\infty}$ norm of the transfer function of the top floor's displacement minimum. Parameters of liquid dampers to be optimized include mass ratio $\mu$, frequency ratio $f$, and damping ratio $d$, of which their physical meanings and optimization ranges are presented as follows.

(1) Mass ratio $\mu$ means the ratio of the mass of the liquid in the container to the one of the whole structure. In the paper, the ratio is supposed to be in the range from $0.1 \%$ to $3 \%$ according to the actual condition.

(2) Frequency ratio $f$ is the ratio of the frequency of the damper to the first frequency of the structure. It is supposed to be in the range from 0 to 2.5.

(3) Damping ratio $d$ denotes the ratio of the damper's damping to its critical one. It is supposed to be in the range from $0 \%$ to $10 \%$.

5.2. First-Order Weighted Function $W_{1}(s)$. For building structures with multiple degrees of freedom, the first few modes will dominate the dynamic response. Generally, the highorder modes are usually ignored and only the first few modes are used for analysis. The low-pass filter can regulate the system response in the low-frequency range and can be used as the weighted function. The influence of the first-order weighted function $W_{1}(s)$ on the optimization result will be analyzed in this section. The first-order weighted function $W_{1}(s)$ can be written as

$$
W_{1}(s)=\frac{k}{s / \omega_{n}+1},
$$

where $k$ means the system gain and $\omega_{n}$ is the cut-off frequency.

5.2.1. The Influence of $\omega_{n}$ on Optimization Results. The preliminary analysis shows that the frequency contents of the top floor's displacement are below $40 \mathrm{rad} / \mathrm{s}$. Given the value of $k$ to be 0.2 and 5 , and $\omega_{n}$ to be $10 \mathrm{rad} / \mathrm{s}, 30 \mathrm{rad} / \mathrm{s}$, and $40 \mathrm{rad} / \mathrm{s}$, then a series of frequency response curves of $W_{1}(s)$ can be obtained, as shown in Figures 3 and 4. 


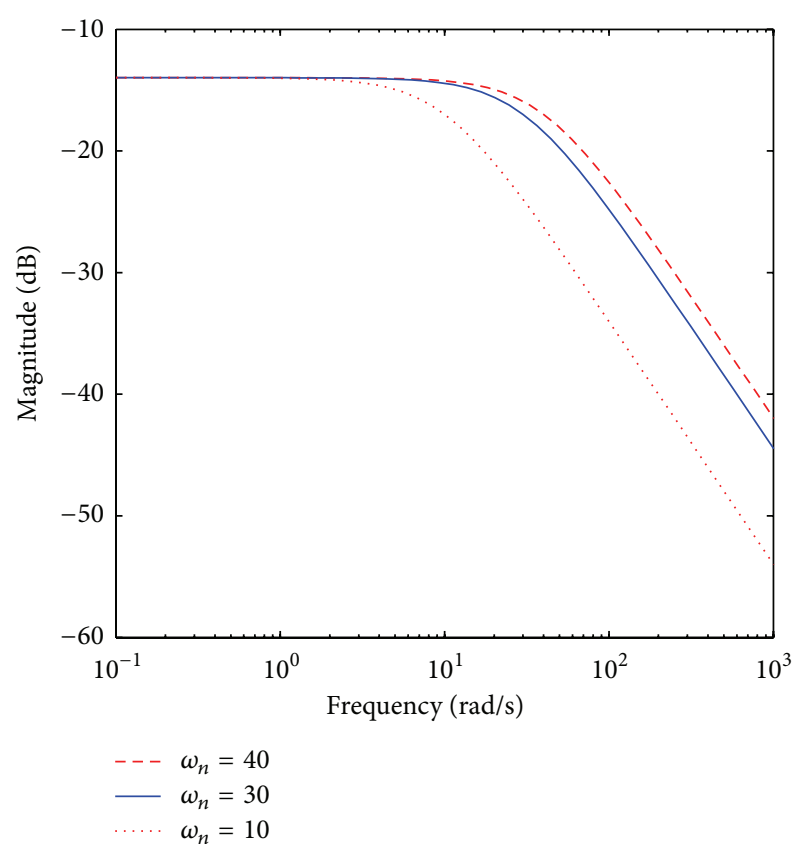

FIGURE 3: Frequency response curve of $W_{1}(k=0.2)$.

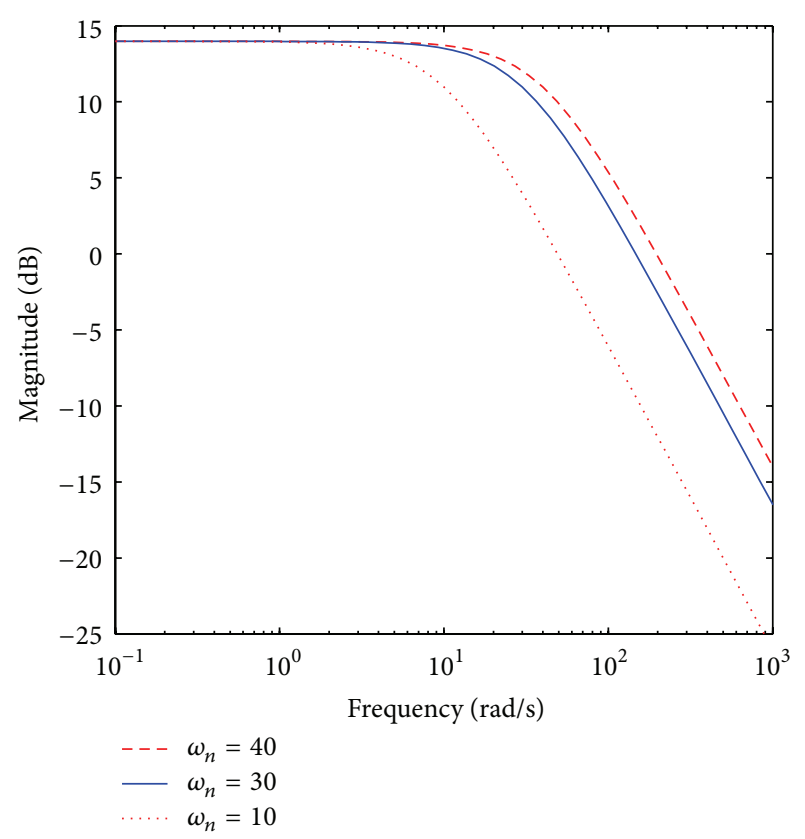

FIGURE 4: Frequency response curve of $W_{1}(k=5)$.

The parameters of TLCD with the above weighted functions are optimized by genetic algorithm and the results are shown in Table 1, in which $\gamma_{\infty}$ means the $H_{\infty}$ norm of the system with optimized values. It can be seen from Table 1 that the values of $\omega_{n}$ and $k$ have significant influences on the optimal mass ratio and frequency ratio of TLCD. The frequency response curves of the top floor's displacement for the structure without control and with TLCD control in different optimal parameters are shown in Figures 5 and 6. It can be
TABLE 1: The optimal parameters of TLCD.

\begin{tabular}{cccccc}
\hline$k$ & $\omega_{n}$ & $\mu$ & $f$ & $d$ & $\gamma_{\infty}$ \\
\hline \multirow{3}{*}{0.2} & 10 & 0.018016 & 0.90971 & 0.099155 & 0.0074883 \\
& 30 & 0.016761 & 0.93214 & 0.099347 & 0.0097854 \\
& 40 & 0.013865 & 0.94394 & 0.099712 & 0.010142 \\
\hline \multirow{3}{*}{5} & 10 & 0.023371 & 0.88797 & 0.098486 & 0.18629 \\
& 30 & 0.015675 & 0.93541 & 0.096908 & 0.24828 \\
& 40 & 0.018858 & 0.92501 & 0.099791 & 0.24220 \\
\hline
\end{tabular}

TABLE 2: The optimal parameters of liquid dampers.

\begin{tabular}{cccccc}
\hline$\omega_{n}$ & $k$ & $\mu$ & $f$ & $d$ & $\gamma_{\infty}$ \\
\hline 10 & 0.2 & 0.018016 & 0.90971 & 0.099155 & 0.0556 \\
10 & 2 & 0.027219 & 0.87352 & 0.09968 & 0.0554 \\
10 & 5 & 0.01647 & 0.9038 & 0.099394 & 0.0556 \\
10 & 10 & 0.019613 & 0.90336 & 0.09991 & 0.0500 \\
\hline
\end{tabular}

found from the figures that the top floor's displacement of the structure can be suppressed obviously with TLCD control. For the controlled structure with optimized parameters in consideration of the weighted function, compared with the one without consideration of the weighted function, the peak response reduces the most when $\omega_{n}$ is $10 \mathrm{rad} / \mathrm{s}$.

5.2.2. The Influence of $k$ on Optimization Results. Given the value of $\omega_{n}$ as $10 \mathrm{rad} / \mathrm{s}$ and $k$ as $0.2,2,5$, and 10 , respectively, the optimal parameters of liquid dampers can be obtained by GA, as shown in Table 2. The corresponding frequency response curves are shown in Figure 7.

It can be seen from Table 2 that the variation of $k$ has significant influences on the optimal value of the mass ratio $\mu$ and little influence on the frequency ratio $f$ and damping ratio $d$. Figure 7 shows that the structural displacement can be effectively controlled with optimized TLCD parameters and the best control case is the one optimized with the firstorder weighted function of $\omega_{n}=10 \mathrm{rad} / \mathrm{s}$ and $k=2$.

5.3. Second-Order-Weighted Function. The second-order weighted function can be written as

$$
W_{2}(s)=\frac{k}{\left(s / \omega_{n}\right)^{2}+2\left(\zeta / \omega_{n}\right) s+1} .
$$

With fixed $k=2$ and $\omega_{n}=10 \mathrm{rad} / \mathrm{s}$, the effect of structural response by different values of $\zeta$ is analyzed in the following. Take $\zeta$ as $0.1,0.2$, and 0.5 , and then a series of frequency response curves of second-order weighted function can be obtained as shown in Figure 8.

With the second-order weighted function, the parameters of the tuned liquid temper are optimized by genetic algorithm. The results are shown in Table 3 , and the corresponding frequency response curves in are shown Figure 9. Table 3 shows that the optimized mass ratio $\mu$ decreases and better control effect can be achieved with the increasing of $\zeta$. Figure 9 shows that the top floor's response is suppressed effectively with optimized TLCD parameters. 


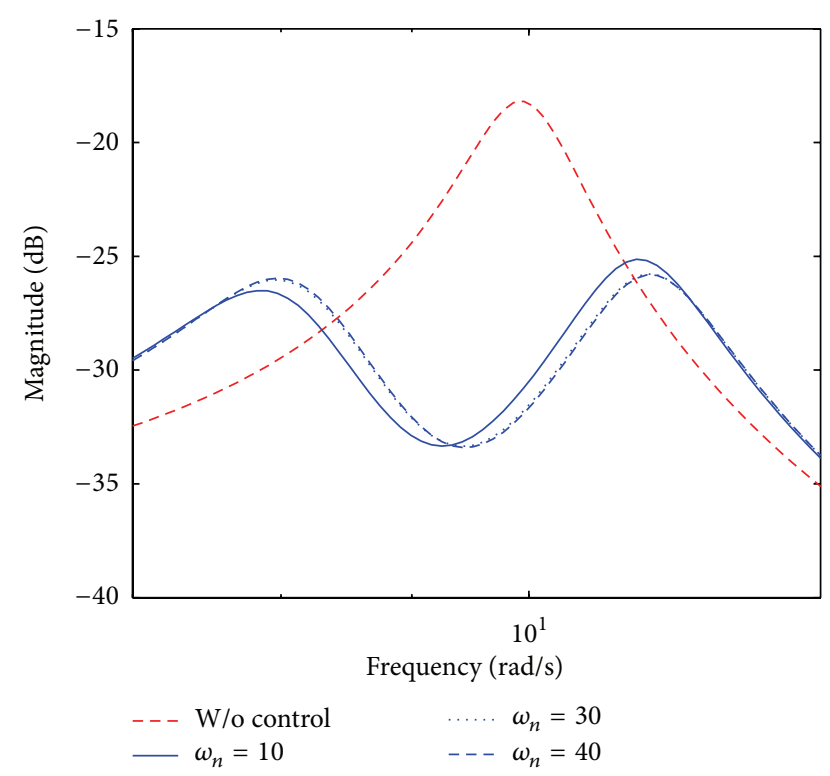

FIGURE 5: Frequency response curve of top floor's displacement $(k=$ 0.2 ).

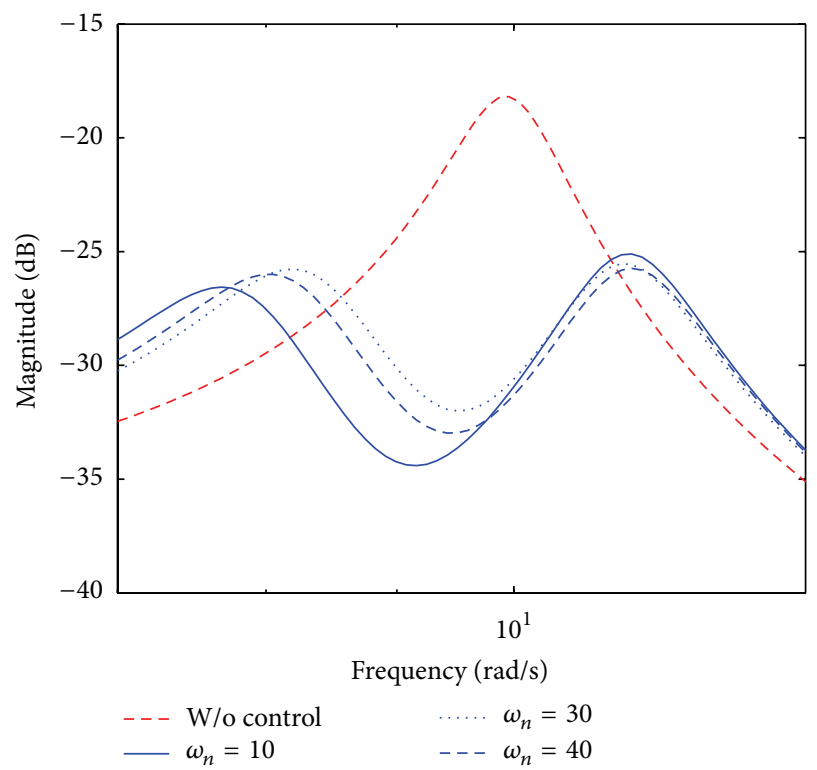

FIGURE 6: Frequency response curve of top floor's displacement $(k=$ 5).

TABLE 3: The optimal parameters of liquid dampers.

\begin{tabular}{ccccc}
\hline$\zeta$ & $\mu$ & $f$ & $d$ & $\gamma_{\infty}$ \\
\hline 0.1 & 0.028854 & 0.92344 & 0.099003 & 0.25339 \\
0.2 & 0.027841 & 0.89932 & 0.099837 & 0.19396 \\
0.5 & 0.011828 & 0.92507 & 0.098664 & 0.10967 \\
\hline
\end{tabular}

Different weighted functions result in the different optimized parameters and different dynamic response curves. The best control performance can be achieved with the $\zeta$ of 0.1 .

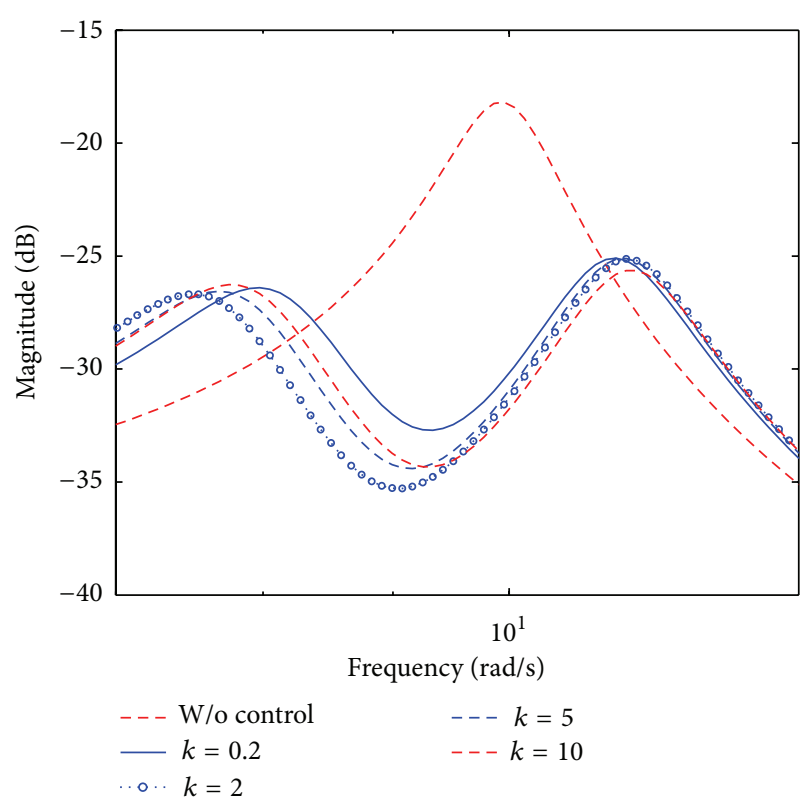

FIGURE 7: Frequency response curve of top floor's displacement.

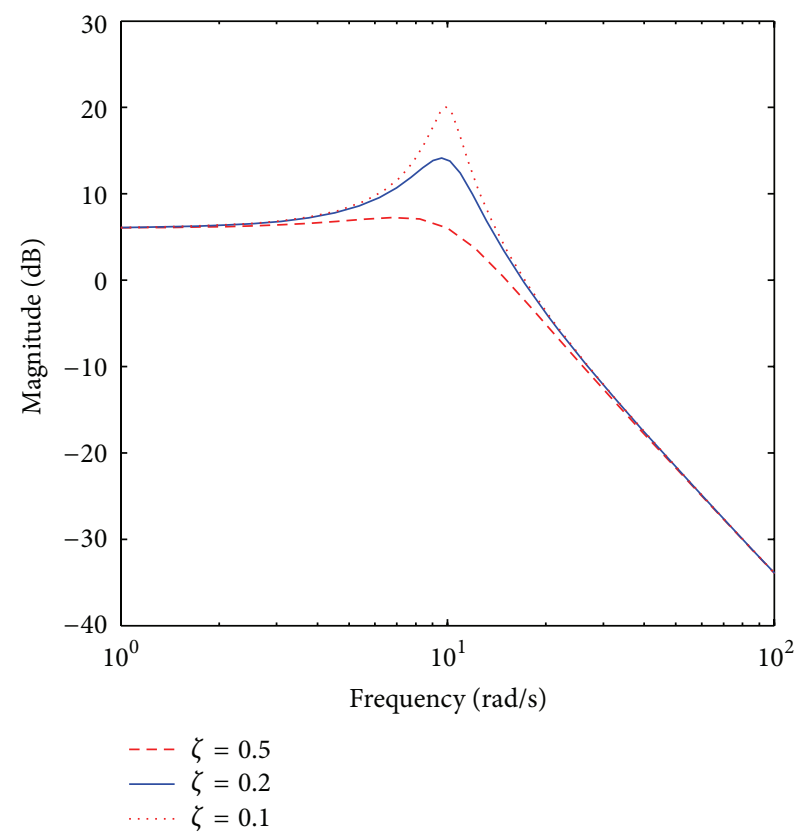

FIGURE 8: Frequency response curve of $W_{2}$.

To achieve the better vibration control effect, the use of the first-order and second-order weighted function is compared as follows. The mathematical formulation of the firstorder weighted function $W_{1}(s)$ and second-order weighted function $W_{2}(s)$ is expressed by $W_{1}(s)=2 /((s / 10)+1)$ and $W_{2}(s)=2 /\left(\left(s^{2} / 100\right)+(0.2 / 10) s+1\right)$. The frequency response curves of $W_{1}(s)$ and $W_{2}(s)$ are shown in Figure 10. The frequency response curves of top floor's displacement and acceleration with optimized TLCD parameters weighted by $W_{1}(s)$ and $W_{2}(s)$ are shown in Figures 11 and 12 . 


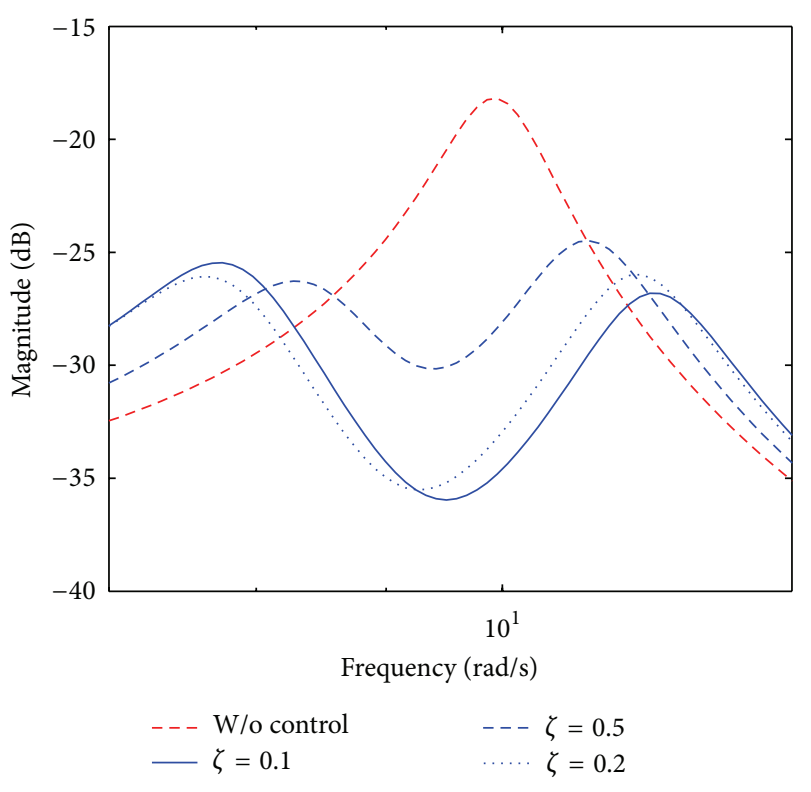

FIGURE 9: Frequency response curve of top floor's displacement.

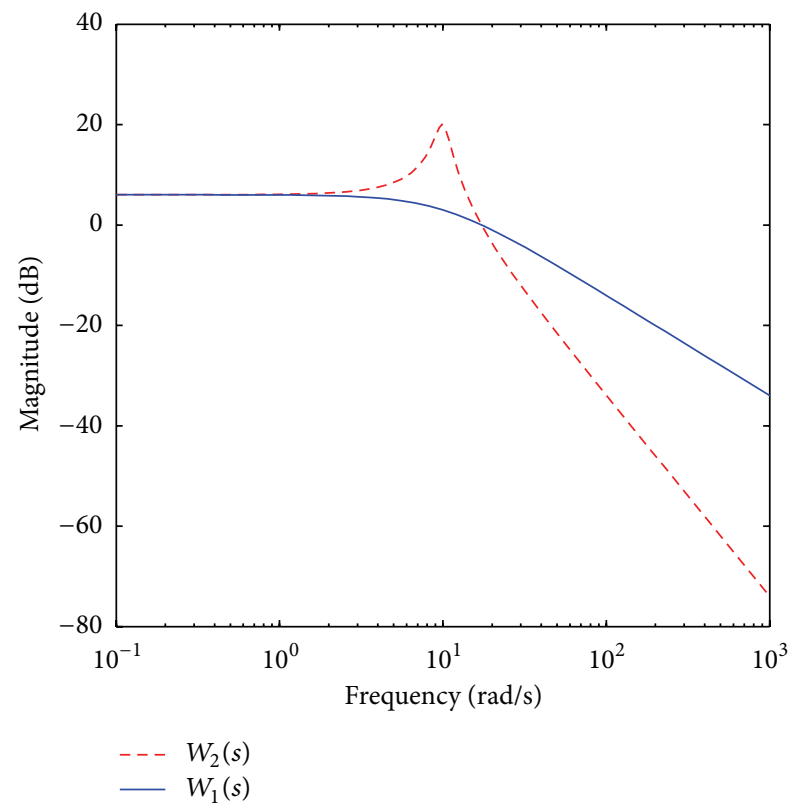

Figure 10: Frequency response curves of $W_{1}(s)$ and $W_{2}(s)$.

It can be seen from the figures that there is little difference for the control results with optimized TLCD parameters weighted by the first-order weighted function or the secondorder one. Hence, the low-order weighted function should be selected to facilitate the controller design.

5.4. Time History Analysis. To verify the control performance of TLCD with optimized parameters, the seismic responses of the 3-story building are analyzed in the time domain. Four earthquake records, Kobe, El Centro, Northridge, and Hach, are used as excitation for different sites. The mass ratio,

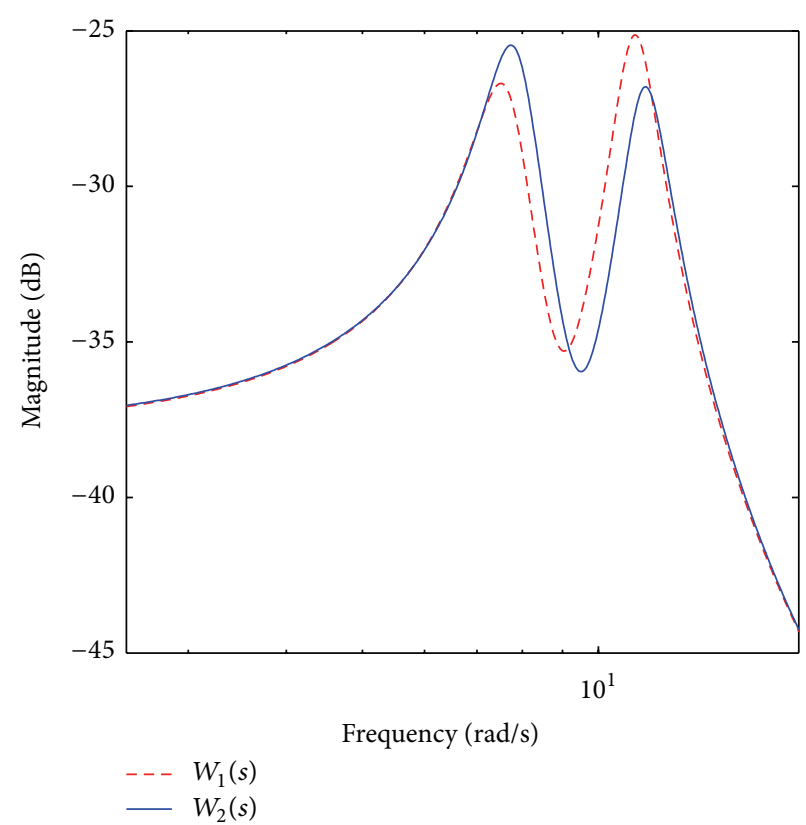

FIGURE 11: Frequency response curve of top floor's displacement.

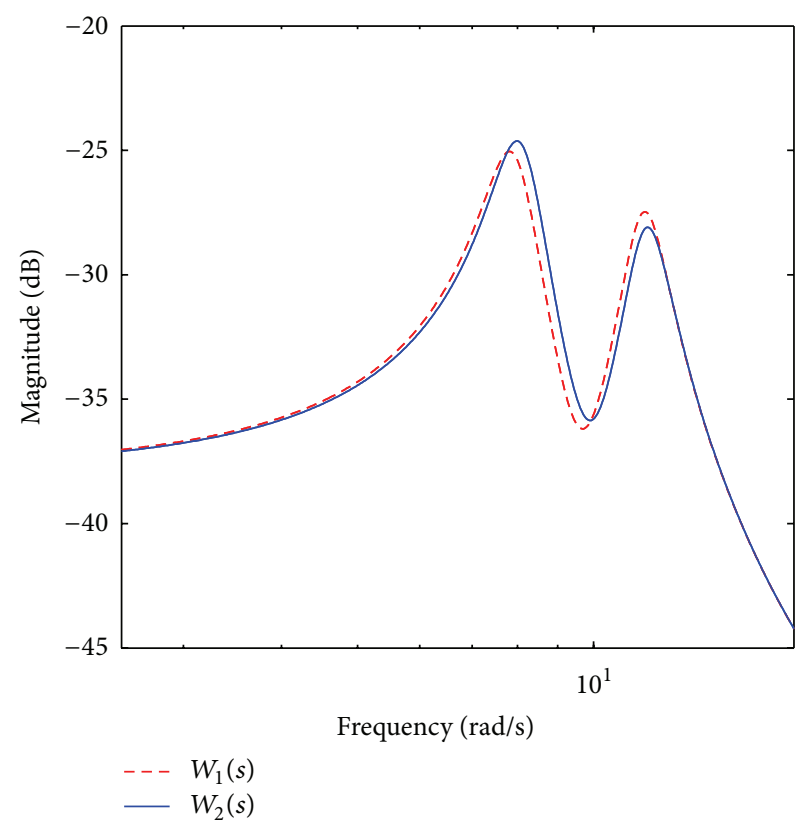

FIGURE 12: Frequency response curve of top floor's acceleration.

frequency, and damping ratio of TLCD are $0.013865,0.94394$, and 0.099712 , as shown in Table 1. The time histories of top floor's displacement and acceleration are shown in Figures 13, $14,15,16,17,18,19$, and 20 . The detailed values of seismic responses and reduction ratios of the structure at different earthquake records are listed in Table 4. From these figures and the table, it can be concluded that the structural response can be effectively reduced subjected to earthquake excitation at different sites. 


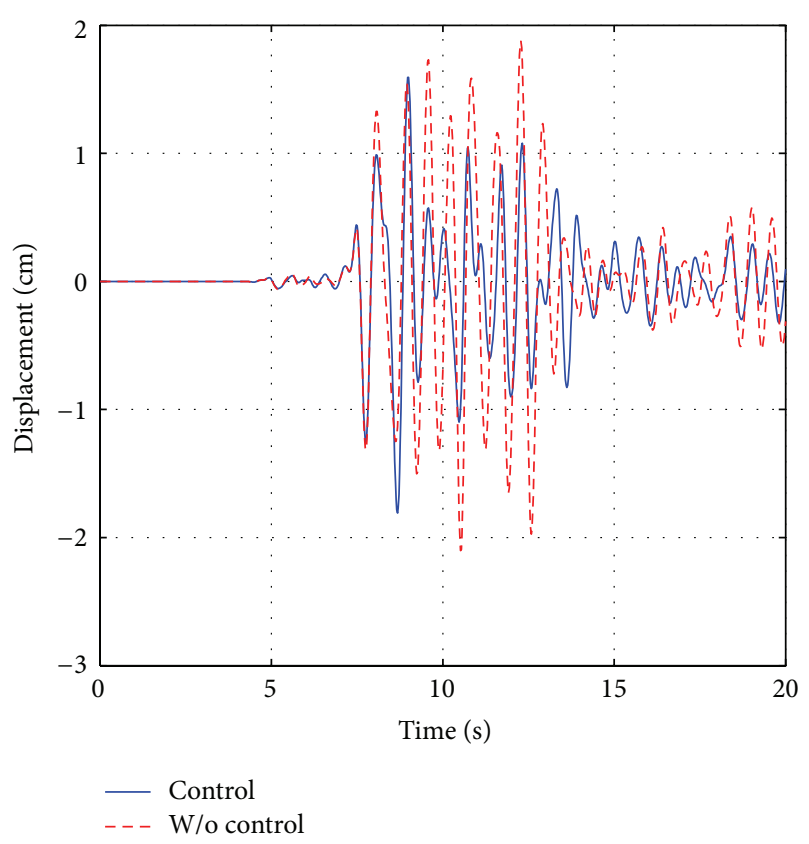

FIgURE 13: Time history of top floor's displacement (Kobe wave).

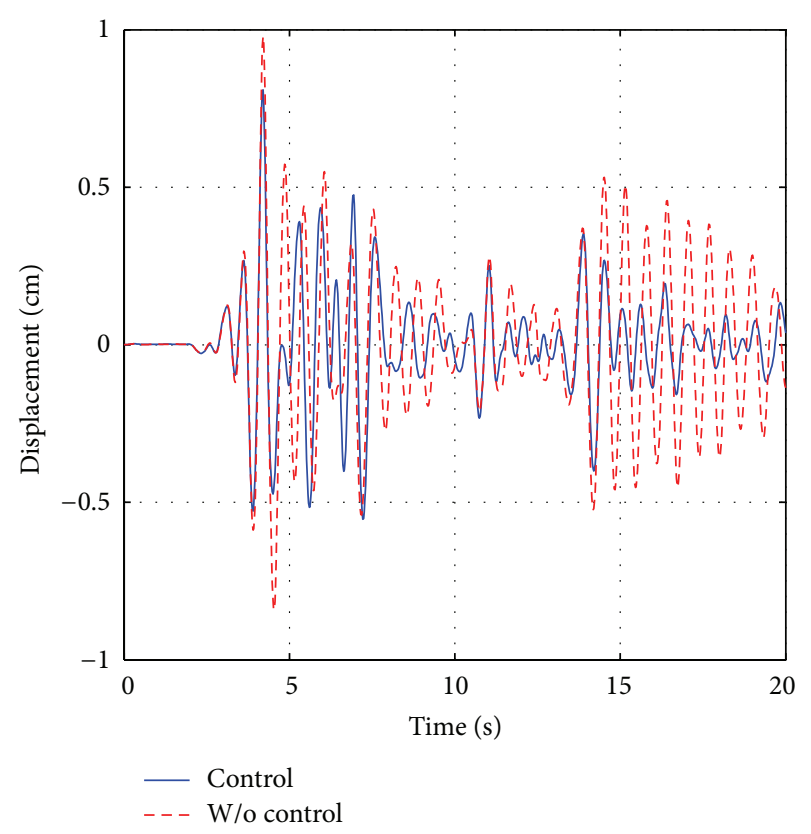

FIgURE 14: Time history of top floor's displacement (EL Centro wave).

\section{Conclusions}

The paper proposed a more general and effective method to optimize the parameters of tuned liquid column dampers (TLCD) based on Genetics Algorithm (GA) and $H_{\infty}$ norm. The weighted functions are necessary in the optimization process. For the weighted function of earthquake excitation, the square root of the Kanai-Tajimi spectrum is suggested. For the weighted function of output, the first-order function

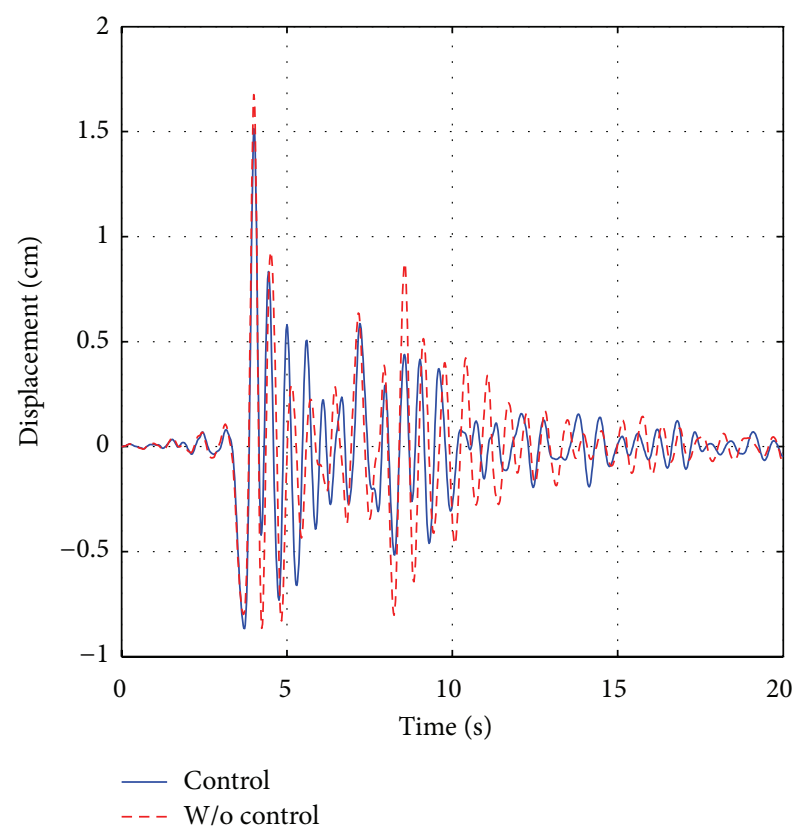

FIgURE 15: Time history of top floor's displacement (Northridge wave).

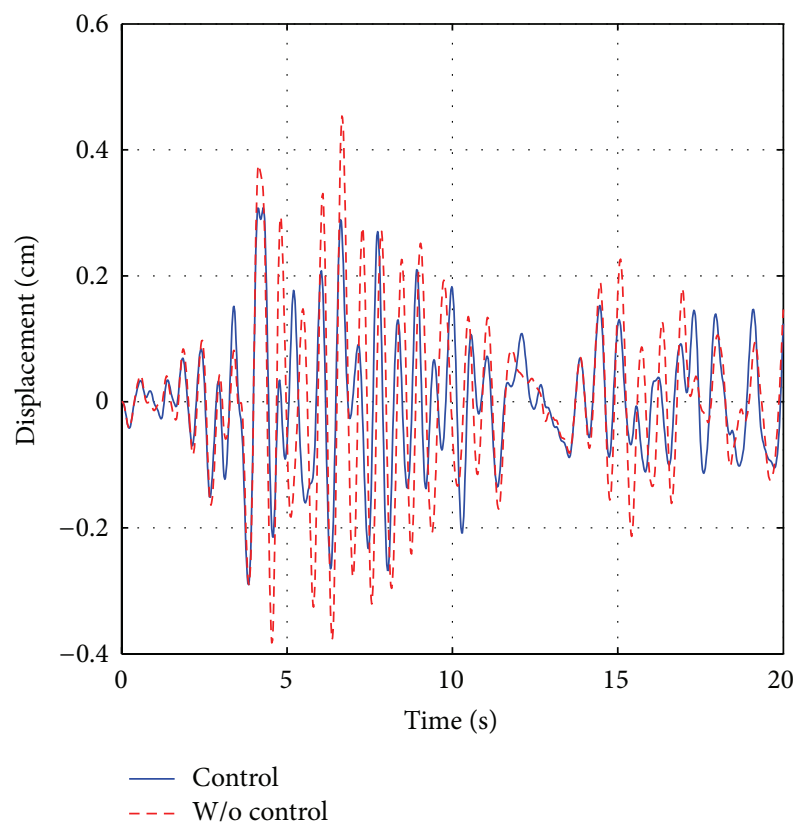

FIGURE 16: Time history of top floor's displacement (Hach wave).

and second-order one are analyzed with different parameters. The results show that the weighted function of output has great influences on the optimized parameters. To facilitate the parameter optimization, the low-order weighted function of the output is suggested. The structure response with optimized liquid dampers subjected to actual earthquake records is analyzed in the time domain. The results show that TLCD with optimized parameters can effectively reduce 
TABLE 4: Reduction ratios of the top story of the structure at different earthquake records.

\begin{tabular}{lcccccc}
\hline $\begin{array}{l}\text { Earthquake } \\
\text { records }\end{array}$ & $\begin{array}{c}\text { Without control } \\
(\mathrm{cm})\end{array}$ & TLCD control $(\mathrm{cm})$ & $\begin{array}{c}\text { Reduction ratio } \\
(\%)\end{array}$ & $\begin{array}{c}\text { Without control } \\
(\mathrm{g})\end{array}$ & $\begin{array}{c}\text { TLCD control (g) } \\
\text { Reduction ratio } \\
(\%)\end{array}$ & $\begin{array}{c}\text { Maximum accelerations } \\
\text { Kobe }\end{array}$ \\
\hline 2.09 & 1.75 & 16.27 & 2.23 & 1.87 & 16.14 \\
El Centro & 0.98 & 0.78 & 20.41 & 1.02 & 0.85 & 16.67 \\
Northridge & 1.73 & 1.52 & 12.14 & 1.83 & 1.60 & 12.57 \\
Hach & 0.48 & 0.37 & 22.92 & 0.48 & 0.39 & 18.75 \\
\hline
\end{tabular}

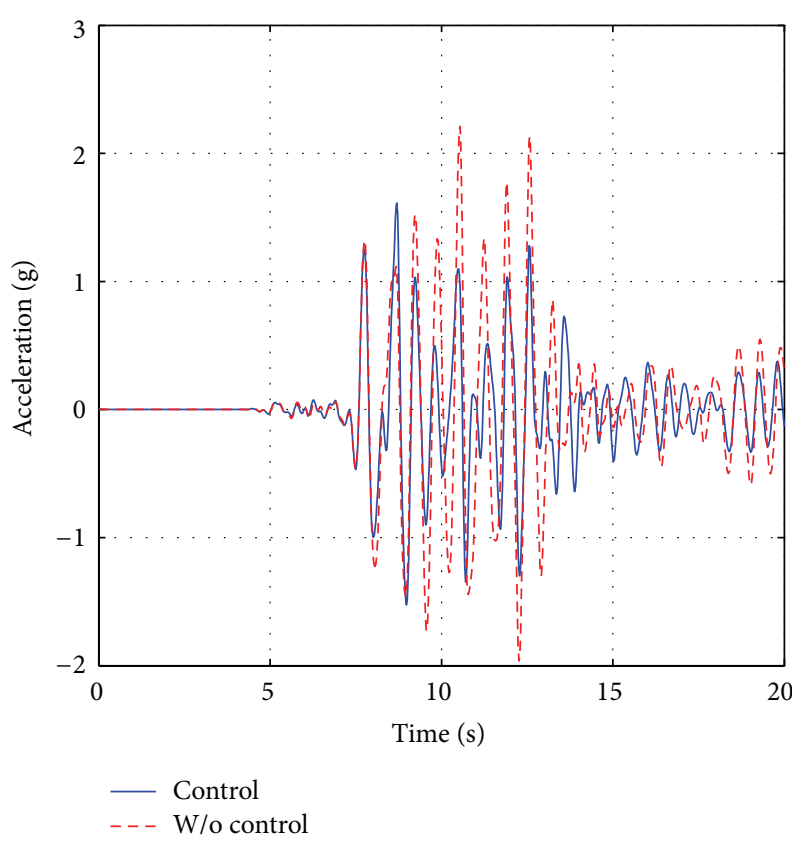

FIGURE 17: Time history of top floor's acceleration (Kobe wave).

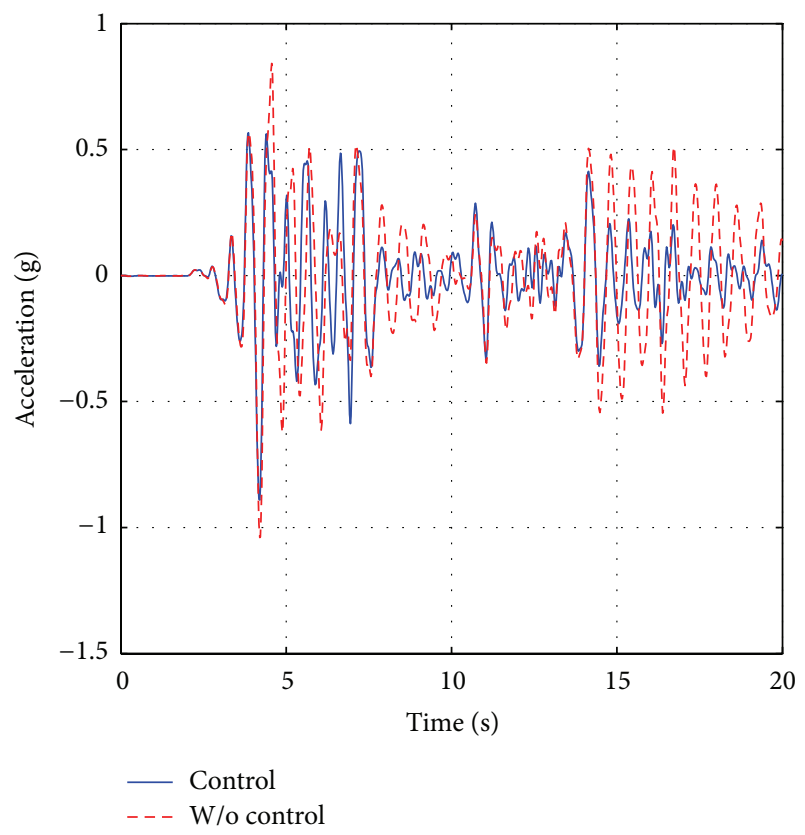

FIGURE 18: Time history of top floor's acceleration (EL Centro wave).

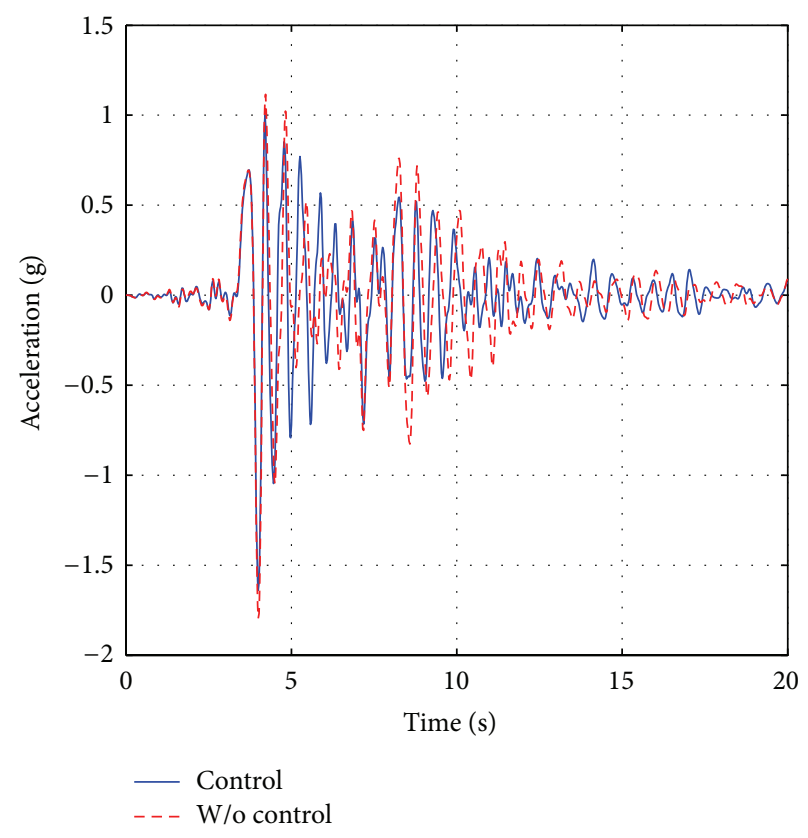

FIGURE 19: Time history of top floor's acceleration (Northridge wave).

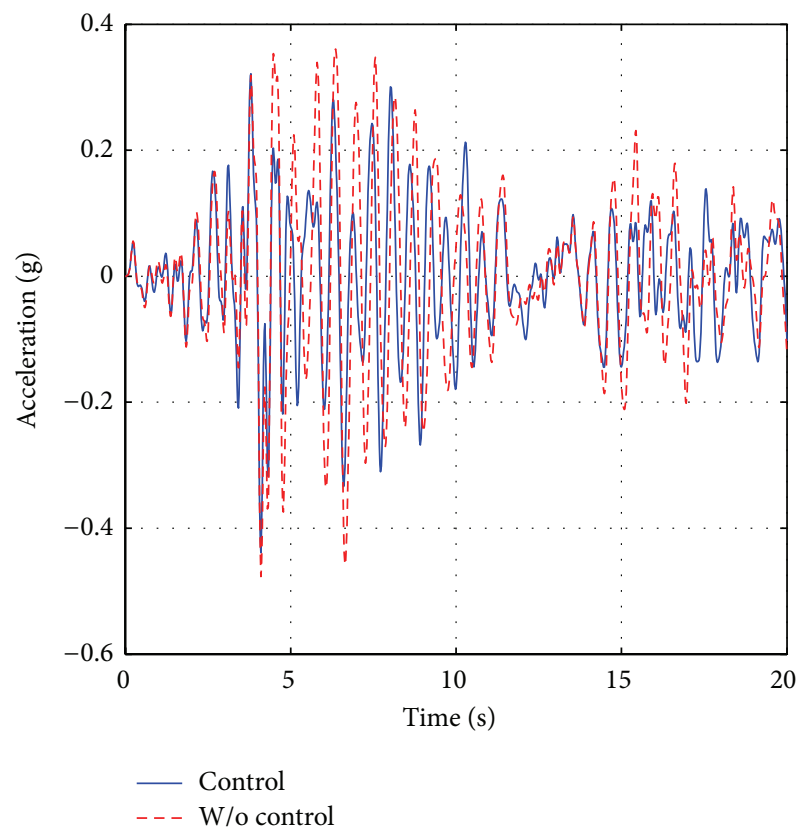

FIGURE 20: Time history of top floor's acceleration (Hach wave). 
the seismic responses at different site types, which verify the generality of the proposed optimization method.

\section{Acknowledgment}

The authors are grateful for the supports from the National Natural Science Foundation of China (Grant nos. 51261120375 and 51121005).

\section{References}

[1] P. A. Hitchcock, K. C. S. Kwok, R. D. Watkins, and B. Samali, "Characteristics of liquid column vibration absorbers (LCVA)-I," Engineering Structures, vol. 19, no. 2, pp. 126-134, 1997.

[2] P. A. Hitchcock, K. C. S. Kwok, R. D. Watkins, and B. Samali, "Characteristics of liquid column vibration absorbers (LCVA)-II," Engineering Structures, vol. 19, no. 2, pp. 135-144, 1997.

[3] W. L. Qu, Z. Y. Li, and G. Q. Li, "Experimental study on U type water tank for tall buildings and high-rise structures," China Journal of Building Structures, vol. 14, no. 5, pp. 37-43, 1993.

[4] F. Sakai, S. Takaeda, and T. Tamake, "Tuned liquid column damper-new type device for suppression of building vibrations," in Proceedings of the International Conference on Europe's High-Rise Building, pp. 926-931, Nanjing, China, 1989.

[5] H. Gao, K. C. S. Kwok, and B. Samali, "Optimization of tuned liquid column dampers," Engineering Structures, vol. 19, no. 6, pp. 476-486, 1997.

[6] S. Yan, H. N. Li, and G. Lin, "Studies on control parameters of adjustable tuned liquid column damper," Earthquake Engineering and Engineering Vibration, vol. 18, no. 4, pp. 96-101, 1998.

[7] C. C. Chang and C. T. Hsu, "Control performance of liquid column vibration absorbers," Engineering Structures, vol. 20, no. 7, pp. 580-586, 1998.

[8] C. C. Chang, "Mass dampers and their optimal designs for building vibration control," Engineering Structures, vol. 21, no. 5, pp. 454-463, 1999.

[9] S. Yan and H. N. Li, "Performance of vibration control for U type water tank with variable cross section," Earthquake Engineering and Engineering Vibration, vol. 19, no. 1, pp. 197-201, 1999.

[10] H. Gao, K. S. C. Kwok, and B. Samali, "Characteristics of multiple tuned liquid column dampers in suppressing structural vibration," Engineering Structures, vol. 21, no. 4, pp. 316-331, 1999.

[11] N. Gluck, A. M. Reinhorn, J. Gluck, and R. Levy, "Design of supplemental dampers for control of structures," Journal of Structural Engineering, vol. 122, no. 12, pp. 1394-1399, 1996.

[12] C. H. Loh, P. Y. Lin, and N. H. Chung, "Design of dampers for structures based on optimal control theory," Earthquake Engineering \& Structural Dynamics, vol. 29, no. 9, pp. 1307-1323, 2000.

[13] A. K. Agrawal and J. N. Yang, "Design of passive energy dissipation systems based on LQR control methods," Journal of Intelligent Material Systems and Structures, vol. 10, no. 12, pp. 933-944, 2000.

[14] A. K. Agrawal and J. N. Yang, "Design of passive energy dissipation systems based on LQR control methods," Journal of Intelligent Material Systems and Structures, vol. 10, no. 12, pp. 933-944, 2000.
[15] J. N. Yang, S. Lin, J.-H. Kim, and A. K. Agrawal, "Optimal design of passive energy dissipation systems based on $\mathrm{H} \infty$ and $\mathrm{H} 2$ performances," Earthquake Engineering \& Structural Dynamics, vol. 31, no. 4, pp. 921-936, 2002.

[16] G. Song, P. Qiao, V. Sethi, and A. Prasad, "Active vibration control of a smart pultruded fiber-reinforced polymer I-beam," Smart Materials and Structures, vol. 13, no. 4, pp. 819-827, 2004.

[17] V. Sethi, M. A. Franchek, and G. Song, "Active multimodal vibration suppression of a flexible structure with piezoceramic sensor and actuator by using loop shaping," Journal of Vibration and Control, vol. 17, no. 13, pp. 1994-2006, 2011.

[18] J. L. Meyer, W. B. Harringtont, B. N. Agrawal, and G. Song, "Vibration suppression of a spacecraft flexible appendage using smart material," Smart Materials and Structures, vol. 7, no. 1, pp. 95-104, 1998.

[19] V. Sethi and G. Song, "Multimodal vibration control of a flexible structure using piezoceramic sensor and actuator," Journal of Intelligent Material Systems and Structures, vol. 19, no. 5, pp. 573582, 2008.

[20] H. Gu, G. Song, and H. Malki, "Chattering-free fuzzy adaptive robust sliding-mode vibration control of a smart flexible beam," Smart Materials and Structures, vol. 17, no. 3, Article ID 035007, 2008.

[21] L. Y. Li, G. Song, and J. P. Ou, "Adaptive fuzzy sliding mode based active vibration control of a smart beam with mass uncertainty," Structural Control \& Health Monitoring, vol. 18, no. 1, pp. 40-52, 2011.

[22] H. Gu and G. Song, "Active vibration suppression of a composite I-beam using fuzzy positive position control," Smart Materials and Structures, vol. 14, no. 4, pp. 540-547, 2005.

[23] K. Zhou, J. C. Doyle, and K. Glover, Robust and Optimal Control, Prentice-Hall, Upper Saddle River, NJ, USA, 1996. 


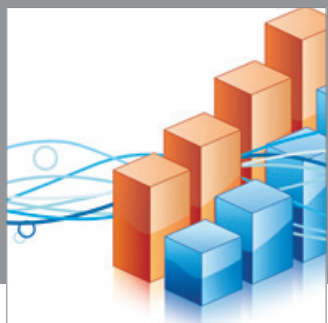

Advances in

Operations Research

mansans

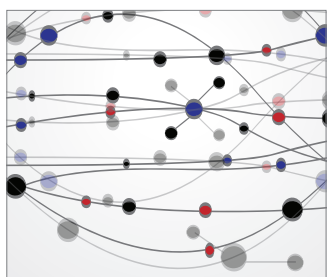

The Scientific World Journal
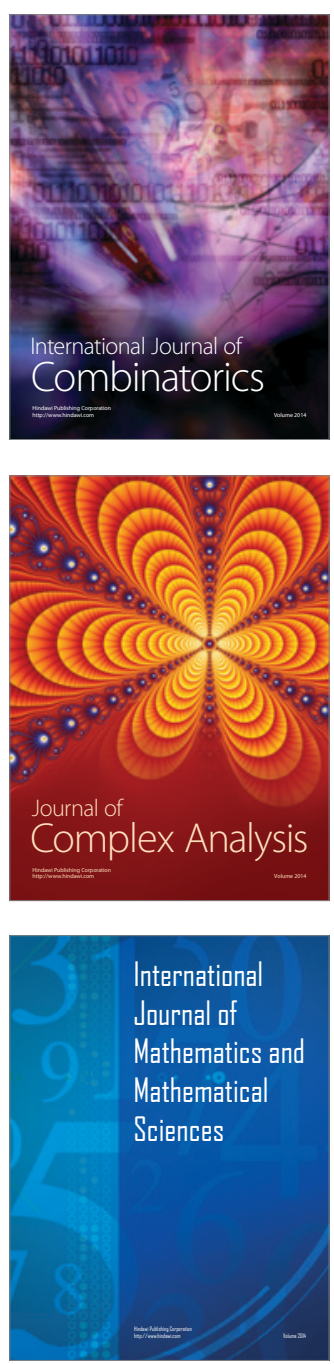
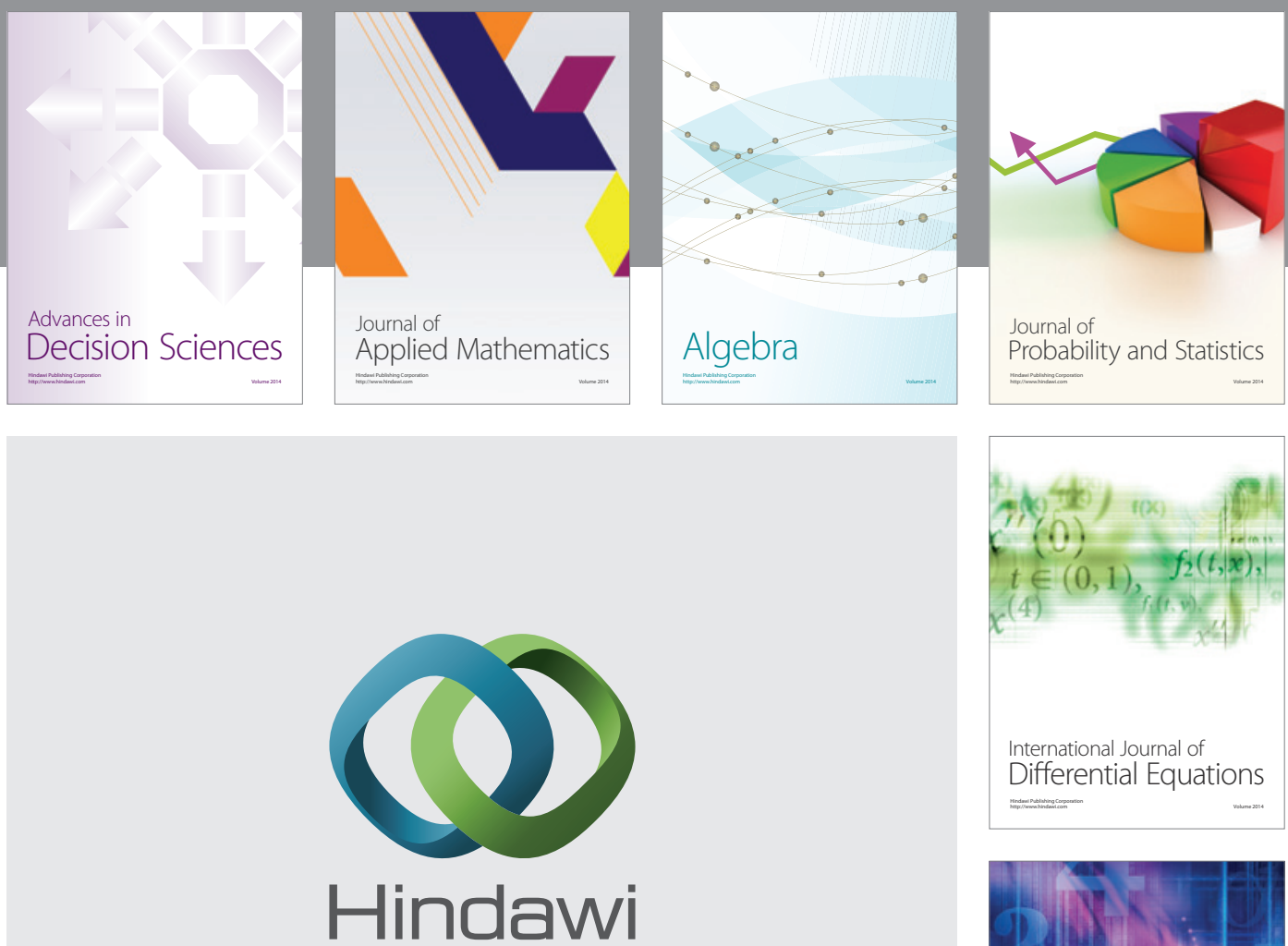

Submit your manuscripts at http://www.hindawi.com
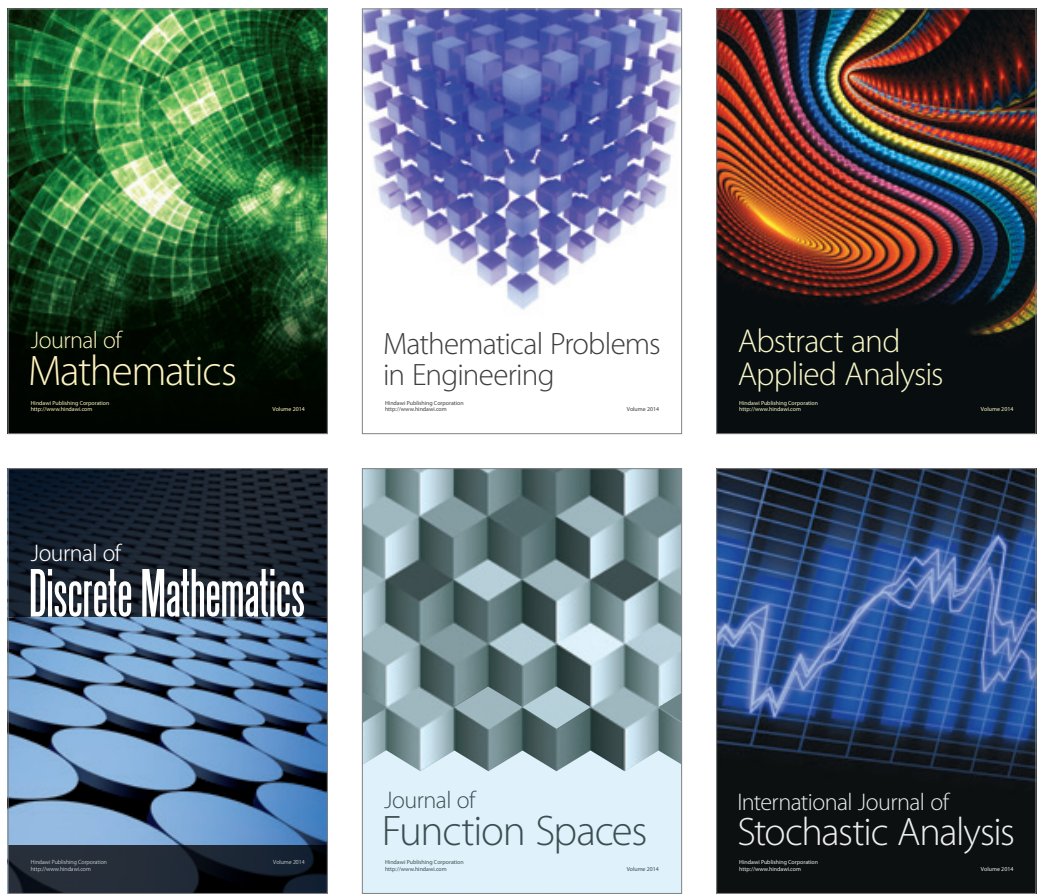

Journal of

Function Spaces

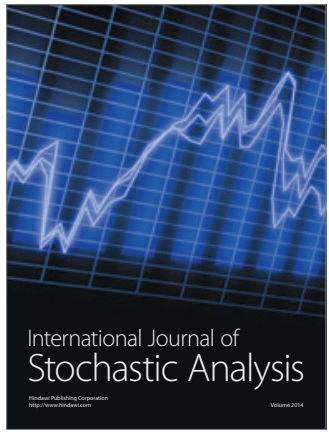

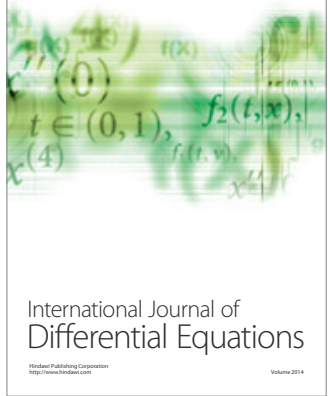
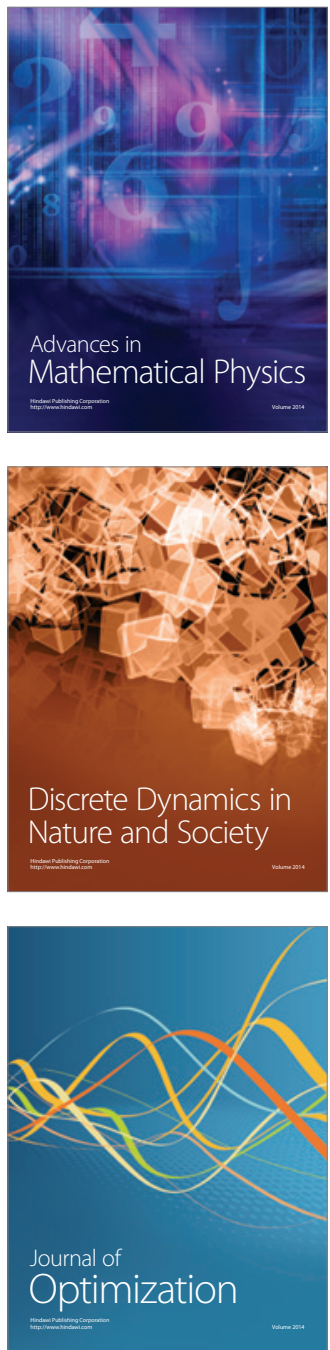